\title{
Selegiline shortage
}

\section{Causes and costs of a generic drug shortage}

E.R. Dorsey, MD, MBA

J.P. Thompson, MPH

E.J. Dayoub, BA

B. George, BS

L.A. Saubermann, PharmD, BCPS

R.G. Holloway, MD, $\mathrm{MPH}$

Address correspondence and reprint requests to Dr. E. Ray Dorsey, University of Rochester Medical Center, 1351 Mount Hope Ave., Suite 223, Rochester, NY 14620 ray.dorsey@ctcc.rochester.edu

\section{ABSTRACT}

Background: In September 2007, shortages of generic selegiline occurred, forcing patients to either switch to more expensive alternatives or forego treatment. We sought to evaluate prescription trends of generic selegiline and to quantify the economic impact of any resulting drug substitution of more expensive alternatives.

Methods: We analyzed proprietary data from IMS Health on monthly prescriptions in the United States for selegiline and potential substitutes from February 2002 through December 2007. Linear regression was used to predict the number of expected prescriptions after August 2007 had a shortage not occurred. The main outcome measures were the changes in prescriptions filled and the economic impact of drug substitution.

Results: Prior to the shortage, total prescriptions filled for generic selegiline decreased $42 \%$, and supply consolidated into one company, Apotex Inc., Toronto, Canada, whose market share increased from $41 \%$ to $83 \%$. During the first 4 months of the shortage, Apotex Inc. filled 10,500 fewer prescriptions than projected and other selegiline manufacturers filled 7,400 more than projected for a net shortage of 3,100 prescriptions. The number of branded selegiline capsules filled during this period increased by 1,800 above projections, and 1,300 prescriptions for generic selegiline were not refilled or substituted. The societal cost of substituting generic selegiline with branded capsules was $\$ 75,000$ over the first 4 months of the shortage.

Conclusions: Generic drug shortages carry economic and health implications. Given ongoing consolidation in the generics drug industry, these shortages may become more common and may require heightened regulatory scrutiny of the generic drug industry. Neurology ${ }^{\circledR} 2009 ; 73: 213-217$

\section{GLOSSARY}

MAO-B = monoamine oxidase type B; PD = Parkinson disease.

Selegiline is a monoamine oxidase type $\mathrm{B}(\mathrm{MAO}-\mathrm{B})$ inhibitor that is effective for treating the symptoms of Parkinson disease (PD). ${ }^{1,2}$ In addition to generic selegiline oral capsules, 2 branded formulations of selegiline (Eldepryl branded capsules; Somerset Pharmaceuticals, Tampa, FL; and Zelapar ${ }^{\circledR}$ orally disintegrating tablets; Valeant Pharmaceuticals International, Aliso Viejo, CA) and another MAO-B inhibitor rasagiline (Azilect ${ }^{\circledR}$; Teva Pharmaceuticals, Petach Tikva, Israel) are currently available for the treatment of PD. ${ }^{3}$

In September 2007, patients in the greater Rochester, NY, area began reporting difficulties filling prescriptions for generic selegiline in retail pharmacies. The shortage was subsequently reported by the American Society of Health-System Pharmacists in October 2007 to be national in scope. ${ }^{4}$ The explanation provided by the principal supplier of generic selegiline was increased demand. ${ }^{4}$ Because of the potential health and financial consequences caused by a generic drug shortage, we sought to 1) evaluate prescription trends of generic selegiline and

From the Department of Neurology (E.R.D., R.G.H.) and Strong Health Pharmacy (L.A.S.), University of Rochester Medical Center; School of Medicine and Biomedical Sciences (J.P.T.), University at Buffalo, NY; Analysis Group, Inc. (E.J.D.), Boston, MA; and College of Arts and Sciences (B.G.), University of Rochester, NY.

Supported by the National Center for Research Resources (http://www.ncrr.nih.gov) of the NIH, and NIH Roadmap for Medical Research (http:// nihroadmap.nih.gov/clinical research/overview-translational.asp) (KL2 RR024136 to Dr. Dorsey and 1 UL1 RR024160-01 to Dr. Holloway).

Disclosure: Author disclosures and disclaimer are provided at the end of the article. 
Figure 1 Monthly generic selegiline prescriptions filled, total and by large manufacturers, February 2002-December 2007

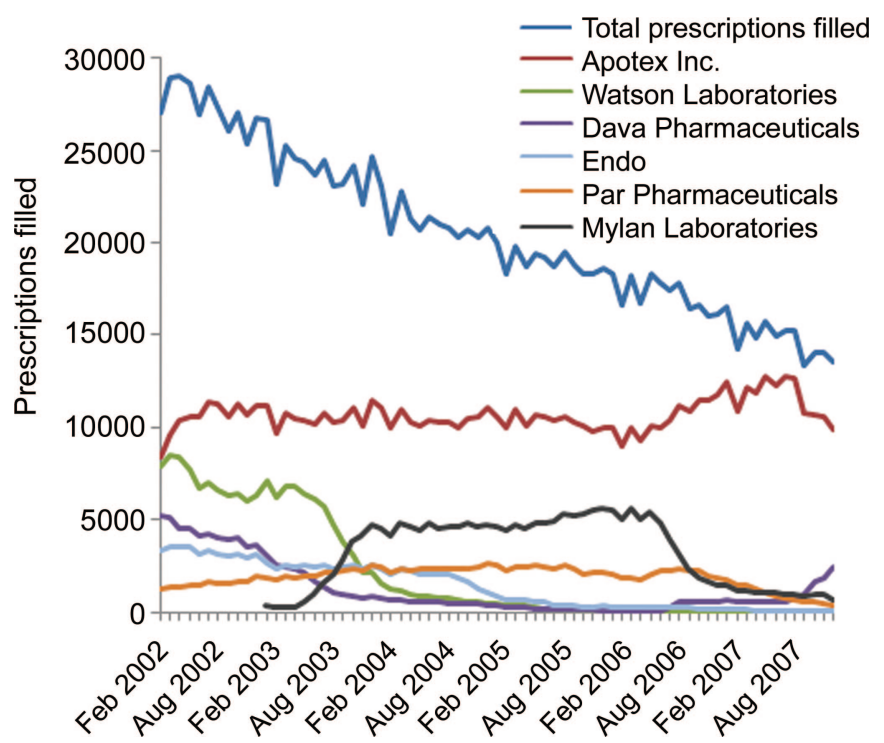

Source: IMS Health, IMS National Prescription Audit ${ }^{\mathrm{TM}}$, 02/2002-12/2007.

alternative $\mathrm{MAO}-\mathrm{B}$ inhibitors before and during the shortage and 2) quantify the economic impact of any resulting drug substitution.

METHODS Prescription data. To evaluate the demand level of generic selegiline both during and prior to the shortage, we analyzed IMS Health National Prescription Audit data on monthly total prescriptions filled for generic selegiline in the United States from February 2002 through December 2007. IMS Health, a strategic consulting and health information company, captures dispensed prescriptions and sales of pharmaceutical products at retail, mail order, and long-term care pharmacies in the United States. ${ }^{5}$ IMS information is used by health care stakeholders to monitor the safety of new medications and improve patient care. We also analyzed National Prescription Audit data of generic selegiline prescriptions filled by manufacturers to determine demand levels experienced by individual firms. ${ }^{6}$ Data for the same time period were used to identify changes in prescriptions filled for branded capsules, orally disintegrating tablets, and rasagiline.

Statistical analysis. To estimate the magnitude of the shortage, simple linear regression (using Microsoft Excel, Redmond, WA) was performed using data for 1 year prior to the shortage (September 2006 through August 2007). Total monthly prescriptions filled was regressed on months to establish the predicted number of prescriptions filled during the initial 4 months of the shortage (September-December 2007). Regression models were calculated for both total generic selegiline and for the major manufacturers of generic selegiline (defined as filling greater than 1,000 prescriptions in any month during the 5.5 years preceding the shortage). Separate regressions were performed for branded capsules, orally disintegrating tablets, and rasagiline. Because rasagiline and orally disintegrating tablets recently entered the market (June 2006 and July 2006, respectively), we used data from the 6 months preceding the shortage to estimate the predicted number of prescriptions filled during the first 4 months of the shortage. Observed prescription levels were considered different from predicted levels if actual prescriptions filled differed by more than $15 \%$ from predicted.

Societal cost of drug substitution. Monthly drug prices were obtained from the Medicare Prescription Drug Plan Finder for Rochester, NY (zip code 14620), for the cheapest national plan available and were as follows: $\$ 20.70$ for $5 \mathrm{mg}$ generic selegiline capsule daily, $\$ 61.50$ for $5 \mathrm{mg}$ branded selegiline capsule daily, $\$ 66.40$ for $1.25 \mathrm{mg}$ orally disintegrating selegiline tablet daily, and $\$ 314.40$ for $1 \mathrm{mg}$ tablet rasagiline. ${ }^{7}$ These prices are similar to those found at national pharmacies (e.g., drugstore.com). ${ }^{8}$

We calculated the societal cost of drug substitution as the product of the number of prescriptions filled by a higher price alternative to generic selegiline (either branded capsules or rasagiline) from September through December 2007 times the price difference between generic selegiline and the more expensive substitutes. We restricted our calculation of societal costs to costs associated with drug substitution. Because prescriptions for generic selegiline went unfilled during the shortage (e.g., were not substituted with branded capsules or rasagiline), we also quantified the value of unfilled generic selegiline prescriptions from September through December 2007.

RESULTS Demand for selegiline. Prior to the shortage (from February 2002 to August 2007), total prescriptions filled for generic selegiline decreased $42 \%$ (from 26,200 to 15,200 prescriptions monthly) (figure 1). During this time, the number of manufacturers supplying more than 1,000 monthly prescriptions decreased from 5 companies to 1 company, Apotex Inc., Toronto, Canada, whose market share increased from $41 \%$ to $83 \%$ (figure 1). From February 2002 through June 2006, prescriptions filled for MAO-B inhibitors approved for the treatment of PD decreased by $41 \%$ from February 2002 (31,000 monthly prescriptions filled) through June 2006 (18,000 monthly prescriptions filled). Following the market entrance of rasagiline and orally disintegrating tablets in mid-2006, monthly prescriptions filled increased to 32,000 in August 2007.

Changes in prescriptions filled during the shortage. During the first 4 months of the shortage, prescriptions filled for generic selegiline decreased by $11 \%$, from 15,200 in August 2007 to 13,600 in December 2007. The change in the number of prescriptions filled varied among manufacturers (figure 2). The number of prescriptions filled by the major manufacturer, Apotex Inc., decreased by 22\% from August 2007 (12,700 prescriptions) to December 2007 (9,900 prescriptions). During this same period, generic selegiline prescriptions filled by other manufacturers rose $45 \%$ (from 2,600 to 3,700 monthly prescriptions filled). Prescriptions filled for branded capsules increased 246\% from August (350 prescriptions) to October 2007 (1,200 prescriptions), but returned to preshortage levels by December 2007 (350 prescriptions). Prescriptions filled for orally disinte- 
Figure 2 Monthly prescriptions filled for monoamine oxidase type B inhibitors approved for treatment of Parkinson disease (shortage first reported in September 2007)

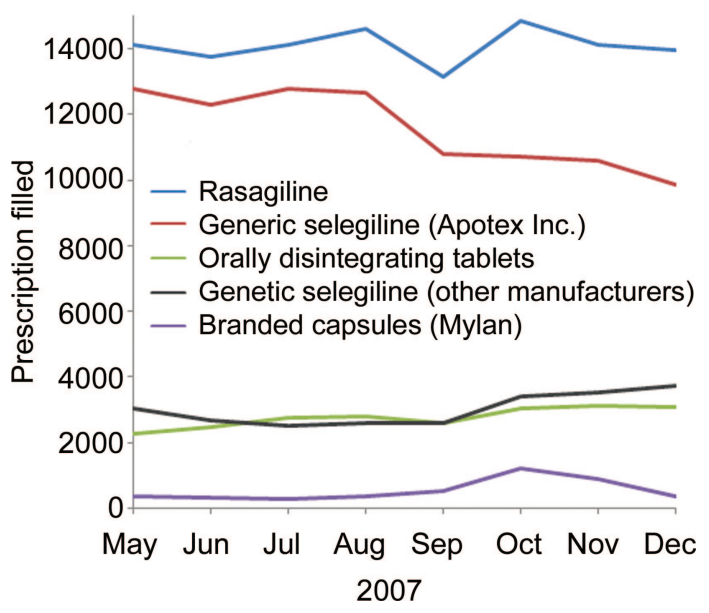

grating tablets and rasagiline did not change substantially during the shortage.

Compared to predicted levels, total generic selegiline prescriptions actually filled between September and December 2007 decreased by 3,100 prescriptions ( $6 \%$ below projected levels). The number of generic selegiline prescriptions filled by Apotex Inc. during the first 4 months of the shortage was 10,500 prescriptions (25\%) below estimated levels, and prescriptions filled by other manufacturers rose by 7,400 prescriptions (26\%) above expected levels (figure 3, A and $\mathrm{B})$. The number of branded capsules filled during this period increased by 1,800 (63\%) above projections (figure 3C). The remaining 1,300 prescriptions (3,100 decrease in filled prescriptions for generic selegiline minus 1,800 increase in filled prescriptions for branded capsules) for generic selegiline were not refilled or substituted during these 4 months.

Societal cost of drug substitution. The societal cost of substituting 1,800 prescriptions for generic selegiline with branded capsules was an estimated $\$ 75,000$ over the first 4 months of the shortage. An additional $\$ 27,000$ in generic selegiline prescriptions were not refilled or substituted during this time.

DISCUSSION Generic drug shortages are common, may become more common as consolidation occurs among generic drug manufacturers, and carry financial and health consequences. In the case of the shortage of generic selegiline, we found that the shortage occurred in the setting of consolidation of the supply of generic selegiline into one manufacturer (Apotex Inc.), which supplied $83 \%$ of the US market. When that manufacturer experienced increased demand, ${ }^{4}$ a drug shortage resulted that was not completely compensated for by other generic drug manufacturers.
Figure 3 Total monthly prescriptions filled for generic selegiline [primary $(A)$ and other manufacturers (B)] and branded capsules (C), September 2006-December 2007
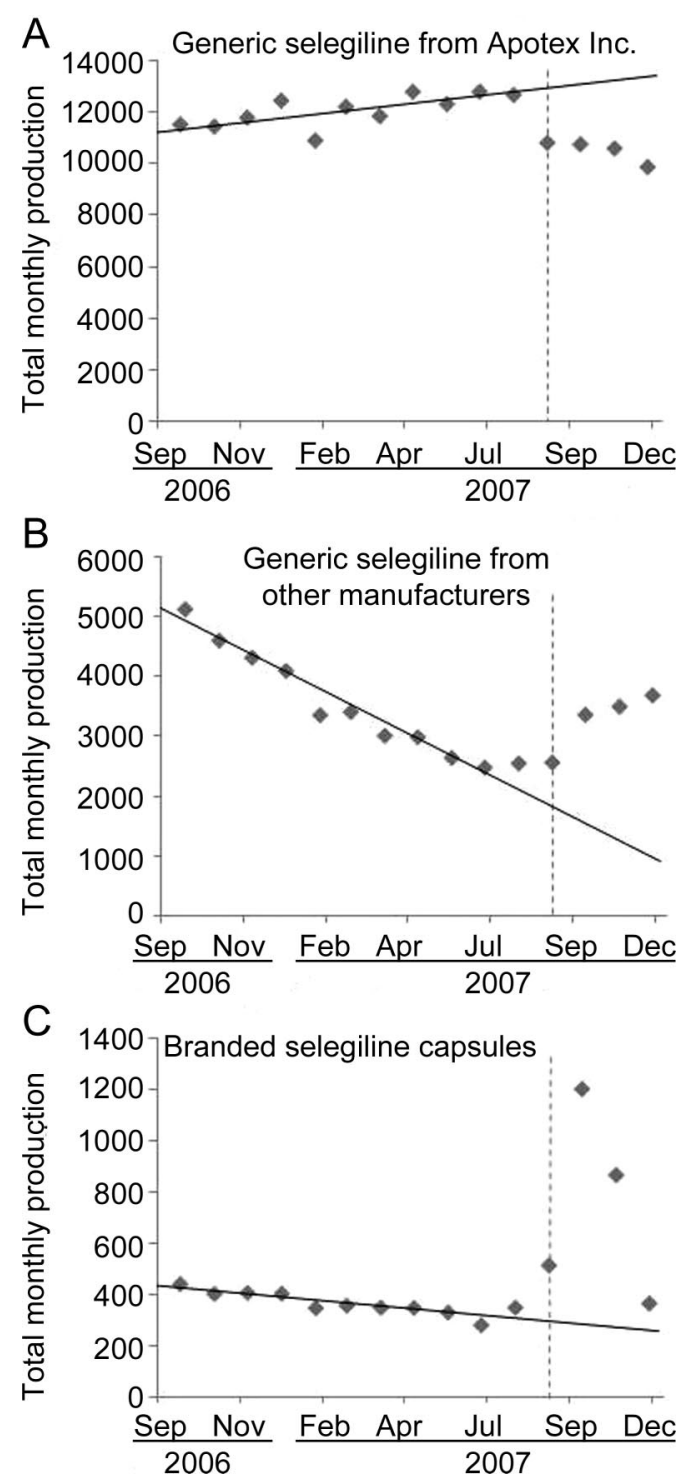

Scale of vertical axis differs between graphs. Source: IMS Health, IMS National Prescription Audit ${ }^{\mathrm{TM}}$, 02/2002-12/ 2008.

Consequently, in this example, a more expensive branded formulation was substituted at a societal cost of at least $\$ 75,000$ and prescriptions went unfilled at uncertain health consequences.

While many factors influence the occurrence and severity of a drug shortage, ${ }^{9}$ a likely cause of the generic selegiline shortage was consolidation of generic selegiline supply manufacturing into one principal company. A major factor in this consolidation may have been the decreased production of generic selegiline by another company (Mylan Inc., Canonsburg, PA) starting in mid-2006. The decrease in generic 
selegiline production by Mylan Inc. may reflect the competing interests and complex relationships between drug manufacturers. For example, Mylan Inc. has financial interests in selegiline in at least 3 different ways: production of generic selegiline tablets, manufacturing and marketing branded capsules (via a 50\% ownership of Somerset Pharmaceuticals, Tampa, FL), and production of transdermal selegiline patches (also through partial ownership of Somerset Pharmaceuticals). ${ }^{10}$ In February 2006, the US Food and Drug Administration approved transdermal selegiline for major depressive disorder, ${ }^{10}$ and generic selegiline tablet prescriptions filled by Mylan Inc. decreased by $80 \%$ over the next year. Therefore, conflicting financial incentives and production constraints affecting Mylan Inc.'s production of generic selegiline may have contributed to the consolidation as Apotex Inc. increased its market share. Previous drug shortages (e.g., naloxone hydrochloride injection and diazepam injection) have also been attributed to market consolidation and subsequent inability of other manufacturers to compensate. ${ }^{11}$

Generic drug shortages, which are increasing in frequency, ${ }^{9}$ may become more common given the ongoing consolidation in the generic drug industry. For example, Teva Pharmaceutical Industries Ltd., Petach Tikva, Israel, the largest public company in the generic drug industry, is acquiring Barr Pharmaceuticals in a multibillion dollar buyout. ${ }^{12}$ Proprietary drug manufacturers are also driving consolidation as they embrace a hybrid model by diversifying their patented drug portfolio with generic drug manufacturing. ${ }^{13}$ Beginning in 2005 (with Switzerland's Novartis acquiring Hexal of Germany), 2 such major consolidations have taken place since May 2007: United States' Mylan Pharmaceuticals acquired Germany's Merck KGaA generics unit, and Japan's Daiichi Sankyo Co. bought a majority stake in India's Ranbaxy Laboratories Ltd. ${ }^{13}$ These transactions may result in competing financial interests within an organization that could hinder the availability of lowerpriced pharmaceutical products.

As this study demonstrates, generic drug shortages carry societal costs. In this case, we quantified the societal cost due to drug substitution of more expensive alternatives to the generic drug. In the selegiline shortage, the principal substitution appeared to be the use of branded capsules, which resulted in an estimated societal cost of $\$ 75,000$ during the first 4 months of the shortage. While approximately $60 \%$ $(1,800$ prescriptions) of the reduction in generic selegiline prescriptions were substituted for a more expensive alternative, an additional 40\% (1,300 prescriptions) went apparently unfilled. These unfilled prescriptions reduced societal expenditures on pharmaceutical costs by an estimated $\$ 27,000$. While this reduced expenditure may represent a societal "savings," it would have to be offset by adverse health consequences from cessation of selegiline, which we did not quantify. Worsening of PD symptoms can occur as soon as 1 month after discontinuing selegiline. ${ }^{1}$

Our estimated economic costs for the selegiline shortage are likely understated for at least 3 reasons. First, costs are only calculated through December 2007, and the shortage did not resolve until August 2008. ${ }^{4}$ Second, individuals who switched to a more expensive preparation may stay on that drug even after the shortage resolves. Third, patients who did not refill or substitute their prescriptions for generic selegiline during the 4-month time period included in this study may need to substitute with a more expensive preparation in the future. Additional economic costs not quantified include inefficiencies and time costs for patients and health care professionals associated with the shortage (e.g., time spent locating pharmacies with generic selegiline or writing new prescriptions for alternative therapies).

Given the risk of shortages occurring with drugs that may not have ready substitutes or may have greater risks associated with their absence, policy measures and heightened attention are needed to prevent future shortages. Additionally, because anticompetitive behavior between drug manufacturers has been identified in the past ${ }^{14}$ and because of the increasing consolidation in the generics industry, vigilance by regulators and continued advocacy for patients are needed, particularly as public payers bear an increasing proportion of pharmaceutical costs in the United States. In the future, the Federal Trade Commission, US Department of Justice, US Food and Drug Administration, and their global counterparts will likely need to consider the likelihood and impact of generic drug shortages resulting from consolidation and take proactive steps to minimize their occurrence. For example, generics whose supply is from one dominant producer could be subjected to heightened scrutiny in their manufacturing processes and production levels. Currently, the Food and Drug Administration does not require notification when discontinuing production unless the firm is the sole manufacturer of a life-saving product. ${ }^{15}$ At a minimum, improved information flow, which surveys indicate is poor, ${ }^{16}$ will be needed among regulators, manufacturers, wholesalers, pharmacists, and clinicians to prevent shortages and their adverse health and economic consequences for society.

\section{AUTHOR CONTRIBUTIONS}

Statistical analyses were conducted by J.P. Thompson. 


\section{ACKNOWLEDGMENT}

The information contained herein is derived in whole or in part from IMS Health Incorporated confidential and proprietary information.

\section{DISCLOSURE}

Dr. Dorsey has served as consultant for and holds stock options in Avid Radiopharmaceuticals, Inc; has received research support from Amarin Neuroscience, Medivation, Inc., NIH, American Parkinson Disease Association, CHDI Foundation, Inc., Michael J. Fox Foundation for Parkinson's Research, National Parkinson Foundation, Robert Wood Johnson Foundation, Parkinson Support Group of Upstate New York, Presbyterian Home for Central New York, and the University of Rochester; and was supported by an American Academy of Neurology Clinical Research Training Fellowship. Mr. Thompson was supported by an American Academy of Neurology 2008 Medical Student Summer Research Scholarship. Mr. Dayoub performed most of his work while at the University of Rochester. Analysis Group, Inc., had no role in preparation or submission of this manuscript. Mr. George reports no disclosures. Dr. Saubermann reports no disclosures. Dr. Holloway serves as consultant for Milliman Guidelines and Maximus, Inc.

\section{DISCLAIMER}

Contents are solely the responsibility of the authors and do not necessarily represent the official views of the National Center for Research Resources or the NIH. The study sponsors played no role in study design, data collection and analysis, writing, or submission of the manuscript. The statements, findings, conclusions, views, and opinions contained and expressed in this article are based in part on data obtained under license from the following IMS Health Incorporated information service: $\mathrm{Na}$ tional Prescription Audit, February 2002 to December 2007, IMS Health Incorporated (all rights reserved) and are not necessarily those of IMS Health Incorporated or any of its affiliated or subsidiary entities.

Received November 6, 2008. Accepted in final form April 8, 2009.

\section{REFERENCES}

1. The Parkinson Study Group. Effects of tocopherol and deprenyl on the progression of disability in early Parkinson's disease. N Engl J Med 1993;328:176-183.

2. The Parkinson Study Group. Effects of deprenyl on the progression of disability in early Parkinson's disease. N Engl J Med 1989;321:1364-1371.

3. Pahwa R, Factor SA, Lyons KE, et al. Practice Parameter: treatment of Parkinson disease with motor fluctuations and dyskinesia (an evidence-based review): report of the Quality Standards Subcommittee of the American Academy of Neurology. Neurology 2006;66:983-995.

4. American Society of Health-System Pharmacists. Current shortages. Available at: http://www.ashp.org/s_ashp/ bulletin.asp? $\mathrm{id}=334 \& \mathrm{CID}=1500 \& \mathrm{DID}=1544 \&$ sort $=0$. Accessed February 8, 2008.

5. Jackevicius CA, Tu JC, Ross JS, Ko DT, Krumholz HM. Use of ezetimibe in the United States and Canada. N Engl J Med 2008;358:1819-1828.

6. IMS Health. IMS National Prescription Audit ${ }^{\mathrm{TM}}, 02 / 2002-$ 12/2007. Extracted January 2008. Available at http://us. imshealth.com/nextgen/enh_NPA.htm. Accessed June 10, 2009.

7. Medicare: The official U.S. government site for people with medicare. Medicare prescription drug plan finder. Available at: http://www.medicare.gov/MPDPF/Public/ Include/DataSection/Questions/MPDPFIntro.asp. Accessed August 1, 2008.

8. Drugstore.com. The uncommon drugstore. Available at: http://www.drugstore.com. Accessed January 6, 2009.

9. Fox ER, Tyler LS. Managing drug shortages: seven years' experience at one health system. Am J Health Syst Pharm 2003;60:245-253.

10. Mylan Laboratories Inc. 2006 Annual Report. Canonsburg, PA; Mylan Laboratories Inc.: 2006.

11. Jensen V, Kimzey LM, Goldberger MJ. FDA's role in responding to drug shortages. Am J Health Syst Pharm 2002;59:1423-1425.

12. Wang SS. Teva to buy US generic rival Barr for $\$ 7.46$ billion: Israeli firm to get improved position in emerging zones. Wall Street Journal. July 19, 2008.

13. Jack A. A bigger dose: why generic drug producers are bulking up. Financial Times. July 22, 2008.

14. Press TA. Executive charged with lying in Plavix case. New York Times. April 23, 2008.

15. Federal Food, Drug, and Cosmetic Act. 21 U.S.C. Section 506 (c), 1997.

16. Wellman GS. National supply-chain survey of drug manufacturer back orders. Am J Health Syst Pharm 2001;58: $1224-1228$.

\section{Resident \& Fellow Section: Call for Teaching Videos}

The Neurology ${ }^{\circledR}$ Resident section is featured online at www.neurology.org. The Editorial Team of this section is seeking teaching videos that will illustrate classic or uncommon findings on movement disorders. Such videos will aid in the recognition of such disorders. Instructions for formatting videos can be found in the Information for Authors at www.neurology.org. 